\title{
Factors influencing perinatal outcome in eclampsia at a tertiary referral hospital
}

\section{Chaitra Sathyanarayana*, Radhamani Somanna}

Department of Obstetrics and Gynecology, Mysore medical college and research institute, Mysore, Karnataka, India

Received: 21 April 2016

Accepted: 25 April 2016

\author{
*Correspondence: \\ Dr. Chaitra Sathyanarayana, \\ E-mail: chaitras7@gmail.com
}

Copyright: (C) the author(s), publisher and licensee Medip Academy. This is an open-access article distributed under the terms of the Creative Commons Attribution Non-Commercial License, which permits unrestricted non-commercial use, distribution, and reproduction in any medium, provided the original work is properly cited.

\section{ABSTRACT}

Background: Perinatal mortality in eclampsia still continues to be high in developing countries mainly due to prematurity and birth asphyxia. This study was conducted at a tertiary referral hospital to analyse the perinatal outcome in eclampsia and identify the associated risk factors.

Methods: A prospective study wherein 170 cases of eclampsia admitted to Cheluvamba Hospital, Mysore, India over a period of one and half years were analysed.

Results: The incidence of eclampsia was $1.08 \% .88 .8 \%$ of the cases were delivered vaginally and $8.2 \%$ by LSCS. Majority of the babies (48.8\%) weighed between 1000-2000 gms. The perinatal mortality rate in this study was $55.3 \%$. Prematurity (61\%), SGA (55\%) and birth asphyxia (55\%) were the most common causes of perinatal morbidity. Birth asphyxia was the commonest cause of perinatal death $(51.2 \%)$ followed by respiratory distress syndrome $(20.93 \%)$, septicemia $(13.95 \%)$ and meconium aspiration syndrome $(6.98 \%)$. Jaundice, pulmonary hemorrhage and intracranial hemorrhage contributed to $2.33 \%$ of early neonatal deaths each. Among various probable risk factors for poor perinatal outcome, $\mathrm{BP} \geq 160 / 110 \mathrm{mmHg}$, gestational age $<28$ weeks, vaginal route of delivery, antepartum eclampsia and convulsion delivery interval $\geq 24$ hours were associated with significantly higher perinatal mortality $(\mathrm{p}<0.05)$.

Conclusions: Strict fetal monitoring and prompt timely intervention may help to reduce the perinatal mortality rate. The NICU facilities have to improve especially in government hospitals so that smaller babies can be taken care of and salvaged.

Keywords: Eclampsia, Perinatal morbidity, Perinatal mortality

\section{INTRODUCTION}

Eclampsia, derived from a Greek word meaning "like a flash of lightening" is a major killer of mother and the fetus even today, especially in developing countries. ${ }^{1,2}$ The incidence varies in different hospitals, regions and countries and reflects the socio-economic condition of a nation and quality of obstetric care. ${ }^{3}$

In the Western world, the incidence of eclampsia is declining and ranges from 1 in 2000 to 1 in 3448 pregnancies. ${ }^{3}$ Its incidence varies from as low as $0.04 \%$ and $0.1 \%$ in the US and UK respectively to as high as
$15 \%$ in some developing countries. ${ }^{4}$ Indian studies have reported an average incidence of $2.7 \% .^{5}$ Though maternal mortality due to eclampsia has reduced over time even in developing countries, perinatal mortality statistics are still disappointing $-14.6 \%$ to $47.4 \%$ in the developing nations. ${ }^{6,7}$ Perinatal morbidity and mortality is mainly due to iatrogenic prematurity. ${ }^{2}$ Low birth weight and birth asphyxia contribute to longer NICU stay and expenses.

Adequate and accessible antenatal care, early diagnosis and management of preeclampsia are necessary to reduce the incidence of eclampsia. But in majority of cases, 
eclampsia comes like a bolt from the blue. Hence, appropriate strategies have to be evolved continuously for the management of eclampsia to achieve a better outcome. By a systematic analysis of the various factors affecting perinatal outcome, we can improve the fetal salvage ability in pregnancies with eclampsia.

Objectives of the study

- To study the clinical profile of eclamptic patients.

- To know the perinatal outcome including morbidity and mortality.

- To analyse the factors affecting perinatal outcome in eclampsia.

\section{METHODS}

A prospective study of 170 cases of eclampsia admitted to Cheluvamba hospital, Mysore, India over a period of one and half years was undertaken after obtaining clearance from the hospital ethical committee.

\section{Inclusion criteria}

- Patients with antepartum convulsions.

- Intrapartum convulsions

- Postpartum convulsions upto 7 days.

\section{Exclusion Criteria}

- Convulsions due to epilepsy and other causes.

- All the women in the study group were subjected to detailed history taking and clinical examination (including fundoscopy) and biochemical investigations.

\section{Interventions}

- General nursing care, maintenance of airway, fluid and electrolyte balance and monitoring of urine output by an indwelling catheter.

\section{- $\quad$ Medical management}

(a) Anti-convulsant regime - To prevent recurrence of convulsions, $\mathrm{MgSO}_{4}$ therapy was used (Pritchard's regime).

(b) Antihypertensives - Nifedipine $10 \mathrm{mg}$ orally was used if blood pressure was greater than 105 $\mathrm{mmHg}$.

\section{- Obstetric management}

Once the patient was stabilized, Bishop's score was assessed. If cervix was favourable, labour was accelerated with ARM and oxytocin. If unfavourable, labour was induced with $\mathrm{PgE}_{1}$ or $\mathrm{PgE}_{2}$. Caesarean section was done for obstetric indications. The perinatal morbidity and mortality was studied in detail. Various factors were studied to see whether they had a significant impact on perinatal outcome.

All babies delivered were followed up during neonatal period for complications.

Statistics were computed using SPSS software version 16. Chi square test, descriptive and cross-tabs used.

\section{RESULTS}

170 cases of eclampsia were studied in Cheluvamba hospital, Mysore Medical College and Research Institute for a period of 18 months. The total number of deliveries in this period was 15691 and the incidence of eclampsia was $1.08 \%$.

To summarize the general demographic characteristics of the patients, $50 \%$ of patients belonged to 20-24 years age group. Eclampsia predominantly affected primis $(77.1 \%)$. $81.8 \%$ of the patients were unbooked and $74.7 \%$ were referred from peripheral hospitals.

Eclampsia was more common in the third trimester. Early onset eclampsia $<28$ weeks contributed to $15.9 \%$ of cases. Antepartum eclampsia was the most common type of eclampsia. It was found that most of the antepartum convulsions occurred preterm while most of those that were intrapartum and postpartum presented at term. Majority of the cases were admitted 3-6 hours after convulsions. In majority of patients with antepartum eclampsia, the induction to delivery interval was 13-24 hours. Only $7.5 \%$ of patients delivered beyond 24 hours after induction.

151 of the cases were delivered by vaginal route $(88.8 \%)$, among these $17(10 \%)$ were instrumental deliveries. The cesarean section rate in eclampsia was $8.2 \%$. Five patients died before delivery (Table 1).

Table 1: Distribution of cases according to mode of delivery.

\begin{tabular}{|lll|}
\hline Mode of delivery & Number of cases & Percentage \\
\hline Vaginal & 134 & 78.8 \\
\hline Forceps & 7 & 4.2 \\
\hline Ventouse & 10 & 5.9 \\
\hline Caesarean section & 14 & 8.2 \\
\hline Died undelivered & 5 & 2.9 \\
\hline Total & 170 & 100 \\
\hline
\end{tabular}

The perinatal outcome was assessed in terms of birth weight, morbidity and mortality. The factors responsible for this outcome were analysed in detail to see whether any interventions to modify the recognized risk factors could help in improving the perinatal outcome. Majority of the babies (48.8\%) weighed between 1000-2000 gms. Only $13.5 \%$ babies weighed more than 2500 gms (Table 2). 
The 170 pregnancies resulted in 170 births (5 pairs of twins, 5 women died undelivered). Table 3 shows the perinatal outcome.

Table 2: Distribution of cases according to birth weight.

\begin{tabular}{|lll|}
\hline Weight (gms) & Number of cases & Percentage \\
\hline$\leq 1000$ & 27 & 15.9 \\
\hline $1001-1500$ & 42 & 24.7 \\
\hline $1501-2000$ & 41 & 24.1 \\
\hline $2001-2500$ & 32 & 18.8 \\
\hline $2501-3000$ & 18 & 10.6 \\
\hline$>3000$ & 5 & 2.9 \\
\hline Not applicable & 5 & 2.9 \\
\hline
\end{tabular}

Table 3: Perinatal outcome.

\begin{tabular}{|c|c|c|c|}
\hline \multicolumn{2}{|c|}{ Perinatal outcome } & Number of cases & Percentage \\
\hline \multirow{3}{*}{$\begin{array}{l}\text { Live } \\
\text { births }\end{array}$} & Preterm & 54 & \multirow{3}{*}{$67.05 \%$} \\
\hline & Term & 60 & \\
\hline & Total & 114 & \\
\hline \multirow{3}{*}{$\begin{array}{l}\text { Still } \\
\text { births }\end{array}$} & Preterm & 46 & \multirow{3}{*}{$30 \%$} \\
\hline & Term & 5 & \\
\hline & Total & 51 & \\
\hline \multirow{3}{*}{$\begin{array}{l}\text { Early } \\
\text { neonatal } \\
\text { deaths }\end{array}$} & Preterm & 31 & \multirow{3}{*}{$25.3 \%$} \\
\hline & Term & 12 & \\
\hline & Total & 43 & \\
\hline \multirow{3}{*}{$\begin{array}{l}\text { Number } \\
\text { of babies } \\
\text { which } \\
\text { survived } \\
\text { at } \\
\text { discharge }\end{array}$} & Preterm & 25 & \multirow[b]{3}{*}{$44.7 \%$} \\
\hline & Term & 51 & \\
\hline & Total & 76 & \\
\hline
\end{tabular}

There were 51 still births and 43 early neonatal deaths. Among the still births 19 patients had absent fetal heart sounds (IUD) on admission. The perinatal mortality rate in this study was $55.3 \%$.

Perinatal mortality rate $=\frac{\text { Still births }+ \text { Early neonatal deaths }}{\text { Total number of births }}$

$$
=\frac{51+43}{170}=\frac{94}{170}=55.3 \%
$$

Hence only 76 of the 114 babies born alive were discharged home.

We analysed the causes for perinatal morbidity. It is outlined in Table 4. Eighty-three babies had some perinatal morbidity and required NICU admission. Prematurity (61\%), SGA (55\%) and birth asphyxia (55\%) were the most common causes of perinatal morbidity. The other common causes were RDS, jaundice, MAS and septicemia.

Among the 83 babies admitted to NICU, 43 died within 1 week of birth (early neonatal deaths). Thirty of these babies $(70 \%)$ were premature and 20 were SGA $(47 \%)$.
Thus, prematurity and SGA were the major underlying contributing factors for mortality. Besides prematurity and SGA, birth asphyxia was the commonest cause of death $(51.2 \%)$ followed by respiratory distress syndrome (20.93\%), septicemia (13.95\%) and meconium aspiration syndrome $(6.98 \%)$. Jaundice, pulmonary hemorrhage and intracranial hemorrhage contributed to $2.33 \%$ of early neonatal deaths each (Table 5).

Table 4: Common causes of perinatal morbidity.

\begin{tabular}{|lll|}
\hline Causes & Number of patients & Percentage \\
\hline Prematurity & 51 & 61 \\
\hline $\begin{array}{l}\text { Small for } \\
\text { gestational age } \\
\text { (SGA) }\end{array}$ & $\begin{array}{l}46 \\
\text { (Preterm-25 } \\
\text { Term-21) }\end{array}$ & 55 \\
\hline Birth asphyxia & 46 & 55 \\
\hline $\begin{array}{l}\text { Respiratory } \\
\text { distress } \\
\text { syndrome (RDS) }\end{array}$ & 10 & 12.05 \\
\hline Jaundice & 6 & 7.23 \\
\hline $\begin{array}{l}\text { Meconium } \\
\text { aspiration } \\
\text { syndrome }\end{array}$ & 6 & 7.23 \\
(MAS) & 6 & 7.23 \\
\hline Septicemia & 4 & 4.82 \\
\hline Anemia & 1 & 1.2 \\
\hline $\begin{array}{l}\text { Subgaleal } \\
\text { hematoma }\end{array}$ & 1 & 1.2 \\
\hline $\begin{array}{l}\text { Intracerebral } \\
\text { hemorrhage }\end{array}$ & 1 & 1.2 \\
\hline $\begin{array}{l}\text { Pulmonary } \\
\text { hemorrhage }\end{array}$ & 1 & 1.2 \\
\hline $\begin{array}{l}\text { Congenital } \\
\text { anomalies }\end{array}$ & 1 & \\
\hline
\end{tabular}

Table 5: The causes of early neonatal deaths.

\begin{tabular}{|ll|l|}
\hline Causes & Number of patients & Percentage \\
\hline Birth asphyxia & 22 & 51.2 \\
\hline RDS & 9 & 20.93 \\
\hline Septicemia & 6 & 13.95 \\
\hline MAS & 3 & 6.98 \\
\hline Jaundice & 1 & 2.33 \\
\hline $\begin{array}{l}\text { Pulmonary } \\
\text { hemorrhage }\end{array}$ & 1 & 2.33 \\
\hline ICH & 1 & 2.33 \\
\hline
\end{tabular}

A number of risk factors were found to be associated with an adverse perinatal outcome in eclampsia. The various factors which were analysed are included in Table 6.

Among these, BP $\geq 160 / 110 \mathrm{mmHg}$, gestational age $<28$ weeks, vaginal route of delivery, antepartum eclampsia and convulsion delivery interval $\geq 24$ hours were associated with significantly higher perinatal mortality $(\mathrm{p}<0.05)$. 
Table 6: Perinatal outcome- probable risk factors and their association.

\begin{tabular}{|c|c|c|c|c|c|}
\hline Risk factors & & No PNM & PNM & Total & p-value \\
\hline \multirow{2}{*}{ Maternal age } & $<25$ years & $64(42.1 \%)$ & $88(58.9 \%)$ & $152(100 \%)$ & \multirow{2}{*}{$\mathrm{p}=0.412^{\mathrm{NS}}$} \\
\hline & $>25$ years & $7(53.8 \%)$ & $6(46.2 \%)$ & $13(100 \%)$ & \\
\hline \multirow{2}{*}{ Parity } & Primi & $55(43.3 \%)$ & $72(56.7 \%)$ & $127(100 \%)$ & \multirow{2}{*}{$\mathrm{p}=0.896^{\mathrm{NS}}$} \\
\hline & Multi & $16(42 \%)$ & $22(57.9 \%)$ & $38(100 \%)$ & \\
\hline \multirow{2}{*}{ Antenatal care } & Booked & $13(41.9 \%)$ & $18(58.1 \%)$ & $31(100 \%)$ & \multirow{2}{*}{$\mathrm{p}=0.891^{\mathrm{NS}}$} \\
\hline & Unbooked & $58(43.3 \%)$ & $44(57 \%)$ & $165(100 \%)$ & \\
\hline \multirow{2}{*}{ Blood pressure } & Severe & $38(35.2 \%)$ & $70(64.8 \%)$ & $108(100 \%)$ & \multirow{2}{*}{$\begin{array}{l}\mathrm{CC}=0.213 \\
\mathrm{p}=0.005^{\mathrm{S}}\end{array}$} \\
\hline & Normal or Mild & $33(57.9 \%)$ & $24(42.1 \%)$ & $57(100 \%)$ & \\
\hline \multirow{2}{*}{ Gestational age } & $<28$ weeks & 0 & $5(100 \%)$ & $5(100 \%)$ & \multirow{2}{*}{$\begin{array}{l}\mathrm{CC}=0.152 \\
\mathrm{p}=0.048^{\mathrm{S}}\end{array}$} \\
\hline & $\geq 28$ weeks & $71(44.1 \%)$ & $89(55.6 \%)$ & $160(100 \%)$ & \\
\hline \multirow{2}{*}{$\begin{array}{l}\text { Mode of } \\
\text { delivery }\end{array}$} & Caesarean & $11(78.6 \%)$ & $3(21.4 \%)$ & $14(100 \%)$ & \multirow{2}{*}{$\begin{array}{l}\mathrm{CC}=0.214 \\
\mathrm{p}=0.005^{\mathrm{S}}\end{array}$} \\
\hline & Vaginal & $60(39.7 \%)$ & $91(60.3 \%)$ & $151(100 \%)$ & \\
\hline \multirow{2}{*}{$\begin{array}{l}\text { Type of } \\
\text { eclampsia }\end{array}$} & AP & $21(25.6 \%)$ & $61(74.4 \%)$ & $82(100 \%)$ & \multirow{2}{*}{$\begin{array}{l}\mathrm{CC}=0.33 \\
\mathrm{p}=0.000^{\mathrm{S}}\end{array}$} \\
\hline & $\mathrm{IP}+\mathrm{PP}$ & $50(60.2 \%)$ & $33(39.8 \%)$ & $83(100 \%)$ & \\
\hline \multirow{2}{*}{$\begin{array}{l}\text { Number of } \\
\text { convulsions }\end{array}$} & $<6$ & $64(43.8 \%)$ & $82(56.2 \%)$ & $146(100 \%)$ & \multirow{2}{*}{$\mathrm{p}=0.562^{\mathrm{NS}}$} \\
\hline & $\geq 6$ & $7(36.8 \%)$ & $12(63.2 \%)$ & $19(100 \%)$ & \\
\hline \multirow{2}{*}{ CDI } & $<24$ hours & $43(45.3 \%)$ & $52(54.7 \%)$ & $95(100 \%)$ & \multirow{2}{*}{$\begin{array}{l}\mathrm{CC}=0.237 \\
\mathrm{p}=0.006^{\mathrm{S}}\end{array}$} \\
\hline & $\geq 24$ hours & $6(18.2 \%)$ & $27(81.8 \%)$ & $33(100 \%)$ & \\
\hline
\end{tabular}

S-Significant; NS-Not significant; PNM - perinatal mortality.

\section{DISCUSSION}

The incidence of eclampsia and total number of deaths from eclampsia have dramatically declined in the developed countries due to improvement in antenatal care, prompt diagnosis and management of preeclampsia. In developing countries, eclampsia and its complications still contribute to significant maternal and perinatal morbidity and mortality.

In the present study, majority of the patients (78.8\%) delivered vaginally without any aid and this was similar to Suman G $(69.6 \%)$ study. ${ }^{8}$ The LSCS rate $(8.2 \%)$ in the present study is comparatively lesser than other studies (Suman G 14\% and Majhi ${ }^{5}$ 10.5\%). ${ }^{8}$ Pritchard in 1984 quoted a LSCS rate of $33 \% .^{9}$

Failed induction was the most common indication. Only 3 of the 14 babies delivered by LSCS in the present study died. This low perinatal mortality in cesarean section cases could also be because all the patients taken for caesarean section had good fetal heart rate at the time of decision for LSCS. But still, several studies have concluded that timely decision making for LSCS has helped in improving the perinatal outcome especially if delivery is not imminent within 6-8 hours after induction ${ }^{10}$.

Majority of the babies of eclamptic mothers weighed between 1000 and 2000 gms in the present study (47\%). This was because majority of the babies were preterm and small for gestational age. Even the term babies weighed lesser (SGA). In a study by Singhal et al, 74\% of babies were preterm. ${ }^{2}$ However, the birth weights were slightly higher in other studies. In a study by Khuman et al, the average birth weight was $1.825 \mathrm{~kg} .{ }^{11}$

The perinatal mortality rate in the present study was $55.3 \%$ which was comparatively higher than other studies. Majority of the Indian studies have noted a perinatal mortality rate around $39 \% .^{2,7,8}$ The PNM rate is much lesser in the Western world (Sibai BM - 11.28\% and Douglas KA $-5.6 \%){ }^{12,13}$ Vigilant fetal monitoring (including electronic fetal monitoring), prompt timely intervention and improvement of neonatal care facilities are needed to reduce the perinatal mortality in the present study.

Majority of the perinatal deaths were related to prematurity in the present study as well as Suman $G^{8}$ study and Sibai study. ${ }^{8,11}$ The other main causes included SGA $(47 \%)$ and birth asphyxia $(51.2 \%)$ in the present study. SGA $(30.4 \%)$ and birth asphyxia $(43.8 \%)$ was seen in Nadkarni study. ${ }^{7}$ Prematurity $(42.9 \%)$ and severe birth asphyxia $(51.2 \%)$ were the most common causes in a study in Tanzania. ${ }^{6}$ Sepsis, neonatal jaundice and respiratory distress syndrome were the other causes of death in all the studies.

Hypertension in pregnancy is associated with constriction of the uterine blood vessels, pathological changes in the spiral arterioles and fibrin deposition, infarcts and other pathological changes in the placenta resulting in retarded fetal growth, fetal hypoxia, IUD and prematurity.

In a nutshell, perinatal complications include:

- Intrauterine death. 
- Fetal growth restriction - poor intrauterine growth is associated with "placental insufficiency". Walters in 1966 stated that complications are related to the duration of hypertension and the presence of proteinuria.

- Prematurity and its associated hazards like neonatal death and pulmonary, renal and hepatic dysfunction. Early labour may occur spontaneously for example in placental abruption, but it is more likely to be due to artificial induction of labour in the maternal interest.

- Brain damage (cerebral palsy) This is likely to be due to anoxia associated with

a) Poor placental blood flow.

b) Maternal hypoxia induced by eclampsia or excessive therapy with sedatives and anticonvulsive drugs.

c) Prolonged and difficult labour.

- Side effects of hypertensive drugs - these induce intestinal ileus, thrombocytopenia, pancreatitis, hypotonia, respiratory depression, etc. ${ }^{14}$

\section{CONCLUSION}

There has been a decline in the incidence of eclampsia in the recent years, with the incidence being $1.08 \%$ in the present study. But, the disease is still associated with significant maternal and more so perinatal morbidity and mortality.

The management protocol has efficiently reduced the maternal mortality to $4.11 \%$ in the present study but more than half the babies born to eclamptic mothers are dying. Strict fetal monitoring (including electronic fetal monitoring) and prompt timely intervention may help to reduce the perinatal mortality rate which was $55.3 \%$. The NICU facilities have to improve especially in government hospitals so that smaller babies can be taken care of and salvaged.

We have to intensify our efforts to make India eclampsia free from the grassroot level. Regular antenatal care, early detection of preeclampsia and its prompt management will go a long way in preventing this catastrophic disease.

Future research should yield efficient strategies to prevent preeclampsia itself so that eclampsia will remain a disease only to be quoted in textbooks.

Funding: No funding sources Conflict of interest: None declared

Ethical approval: The study was approved by the Institutional Ethics Committee

\section{REFERENCES}

1. Chesley LC. Hypertensive disorders in pregnancy. New York: Appleton Century Crofts. 1978: 1-628.

2. Singhal SR, Deepika, Anshu, Nanda S. Maternal and perinatal outcome in severe pre-eclampsia and eclampsia. South Asian Federation of Obstetrics and Gynecology. 2009;1(3):25-8.

3. Sibai BM. Diagnosis, prevention and management of eclampsia. Obstetrics and Gynecology. 2005;105(2):402-10.

4. Aagaard-Tillery K, Belfort MA. Eclampsia morbidity, mortality and management. Clinical Obstetrics and Gynecology. 2005;48:12-20.

5. Majhi AK, Chakraborty PS. Eclampsia - Present scenario in a referral medical college hospital. J Obstet Gynecol of India. 2001;53(3):143-7.

6. Ndaboine EM, Kihunrwa A, Rumanyika R, Beatrice HIm, Massinde AN. Maternal and Perinatal Outcomes among Eclamptic Patients Admitted to Bugando Medical Centre, Mwanza, Tanzania. African Journal of Reproductive Health. 2012;16(1): 35-41.

7. Nadhkarni J, Bahl J, Parekh. Perinatal outcome in pregnancy induced hypertension. Indian Pediatrics. 2001;38:174-8.

8. Suman GS, Somegowda. Maternal and perinatal outcome in eclampsia in a district hospital. Journal of Obstet and Gynaecology of India. 2007;57(4):324-6.

9. Pritchard JA, Cunningham FG, Singe A, Pritchard RN. The Parkland Memorial Hospital protocol for treatment of eclampsia: Evaluation of 245 cases. Am Obstet Gynecol. 1984;148(7):951-63.

10. Rajan R. Recent advances in clinical obstetrics. New Delhi: CBS Publishers. 1997:95-105.

11. Khuman V, Singh RL, Singh RM, Devi UA, Kom T. Perinatal outcome in eclampsia. J Med Soc. 2015;29:12-5.

12. Sibai BM. Eclampsia-maternal and perinatal outcome in 254 consecutive cases. Am Journal of Obstet Gynecol. 1990;163:1079-155.

13. Douglas KA, Redman CWG. Eclampsia in the United Kingdom. British Medical Journal. 1994;309:1395-9.

14. Singh BM, Misra R. Hypertensive disorders in pregnancy. 6th ed. In: Ian Donald's Practical obstetric problems. Misra R, ed. New Delhi: Edward Arnold Ltd. 2007:280-309.

Cite this article as: Sathyanarayana $\mathrm{C}$, Somanna $\mathrm{R}$. Factors influencing perinatal outcome in eclampsia at a tertiary referral hospital. Int J Reprod Contracept Obstet Gynecol 2016;5:1336-40. 